\title{
Strength improvement of lime-treated clay with sodium chloride
}

1 Nor Zurairahetty Mohd Yunus PhD, MSc, BEng (Hons) Senior Lecturer, Geotechnical and Transportation Department, Faculty of Civil Engineering, Universiti Teknologi Malaysia, Skudai, Malaysia (corresponding author: nzurairahetty@utm.my)

2 Dariusz Wanatowski MSc, PhD, CEng, CSci, MIMMM, FICE Professor, School of Civil Engineering, Faculty of Engineering, University of Leeds, Leeds, UK
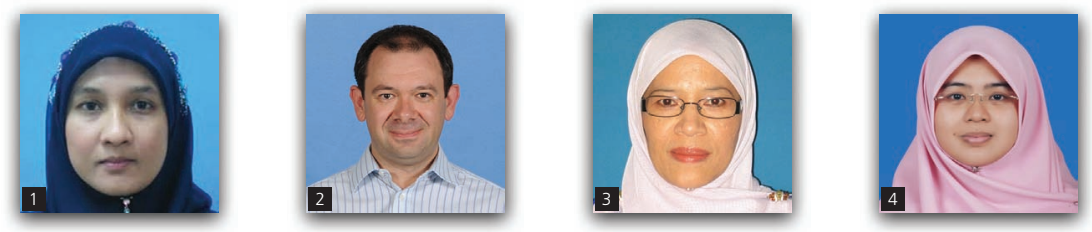

Lime stabilisation of organic clay has often been studied in the past. However, there is some evidence in the literature that the presence of high concentrations of organic matter in clay soil can lessen the chemical reaction between lime and clay minerals and can have detrimental effects on the engineering properties of soil. Hence, in this paper, the stress-strain behaviour and strength properties of organic soil treated with lime and sodium chloride (NaCl) are analysed. A soil mixture, prepared with $5 \%$ lime content and $1.5 \%$ humic acid, was stabilised with varying quantities of sodium chloride $(\mathbf{0 . 5}, \mathbf{2} .0$ and $\mathbf{5 . 0} \%)$. Consolidated undrained and drained triaxial tests were carried out on specimens at curing periods of 7 and $28 \mathrm{~d}$ with applied confining pressures of 50 and $100 \mathrm{kPa}$. Scanning electron microscopy and X-ray diffraction analysis were used to observe the microstructural changes resulting from cementation materials. It was found that the introduction of sodium chloride improved considerably the strength properties of the lime-treated organic clay. The microstructural analysis also confirmed the presence of calcium silicate hydrate in a salttreated organic clay, which was the main contributing factor to the enhanced engineering properties of the clay.

\section{Notation}

$a \quad q$ value that intercepts at $y$-axis from $q-p^{\prime}$ space

$C_{\mathrm{c}} \quad$ compression index

$c^{\prime} \quad$ effective cohesion: $\mathrm{kPa}$

$e_{\mathrm{i}} \quad$ initial void ratio

$m \quad$ gradient of slope $/\left(q / p^{\prime}\right)_{\mathrm{p}}$

$O_{\mathrm{MC}} \quad$ optimum moisture content

$O_{\text {SC }} \quad$ optimum salt content

$p_{\mathrm{c}}^{\prime} \quad$ pre-consolidation pressure

$p_{0}^{\prime} \quad$ overconsolidation ratio

$q_{\mathrm{p}} \quad$ peak deviator stress: $\mathrm{kPa}$

$\left(q / p^{\prime}\right)_{\mathrm{p}}$ peak effective stress ratio

$w_{\mathrm{i}} \quad$ initial water content

$\Delta u \quad$ excess pore water pressure: $\mathrm{kPa}$

$\varepsilon_{\mathrm{a}} \quad$ axial strain

$\varepsilon_{\mathrm{v}} \quad$ volumetric strain

$\sigma_{1} \quad$ major principal stress

$\sigma_{3} \quad$ minor principal stress

$\sigma_{3}^{\prime} \quad$ effective confining pressure: $\mathrm{kPa}$

$\phi^{\prime} \quad$ effective friction angle: ${ }^{\prime}$

\section{Introduction}

There is some evidence in the literature that the occurrence of high concentrations of organic matter, in particular humic acid, in clay soil can weaken the chemical reaction between lime and clay minerals and can have negative effects on the engineering properties of the soil (Chen et al., 2009; Hebib and Farrell, 2003; Kang et al., 2017; Koslanant et al., 2006; Onitsuka et al., 2003; Petry and Glazier, 2004). Sakr and Shahin (2009) demonstrated that soft clay with a high organic content of $14 \%$ can be successfully stabilised with 7\% lime. However, according to Petry and Glazier (2004), the presence of more than $4 \%$ organic matter reduces the compressive strength of lime-stabilised weathered clay. This suggests that some organic compounds do not have a detrimental effect on the cementing reaction. It was reported that although the lime-treated specimens of organic clay exhibited significant strength gained compared to that of the untreated specimens, the probabilities of long-term strength development in the specimens were still indeterminate. This happens because humic acid disturbs the pozzolanic reaction process that occurs between lime and clay by obstructing or slowing it down. It also results in a decrease in the $\mathrm{pH}$ of the mixtures' pore solution.

A highly alkaline environment (if allowed) elongates the duration required for the dissolution of alumina and silica. Therefore, the use of only lime may not be sufficient or effective in stabilising organic soils. Adding a considerable quantity of lime to the soil is an effective way to moderate the unfavourable effects of humic acid. It 
is deemed that addition of lime could neutralise humic acid if an adequate amount of binder is also added. However, this method is not cost-efficient. Another method that could neutralise humic acid is the addition of selected salts, which play the role of additional binders to help lime react during the stabilisation process of organic clay. It has been observed that humic acid coats the clay particles and thereby behaves as a barrier to lime and clay (Abood et al., 2007; Ahnberg, 2004; Koslanant et al., 2006; Kuno et al., 1989). The addition of salts to the organic clay coagulates the soil, thereby causing the clay particles to expose themselves to the lime for pozzolanic reactions.

Previously, it was found that more than $1 \%$ humic acid content in clay may render the lime stabilisation process ineffective (Harris et al., 2009; Huat et al., 2005; Koslanant et al., 2006; Zhu et al., 2009). More recently, it has been reported that there is a significant loss of strength in lime-treated organic clay that has a humic acid composition equal to or greater than 1.5\% (Mohd Yunus et al., 2013a; Mokhtar and Swamy, 2010). Hence, it is important to consider the possible advantages of using additives or additional binders for enhancing the lime stabilisation process in organic clays with a noticeable humic acid content. It was reported in the literature that salt additives, such as sodium chloride $(\mathrm{NaCl})$, can be used as an admixture so that the characteristics of the lime-treated organic clay can be improved (Asghari et al., 2003; Davoudi and Kabir, 2011; Marks and Haliburton, 1999; Modmoltin and Voottipruex, 2009; Murty and Krishna, 2007; Onitsuka et al., 2002, 2003; Ramana and Hari Krishna, 2006; Ramesh et al., 1999; Sharma et al., 2008; Stipho, 1989). The salt additives, being more readily soluble in water than lime, provide the required cations that are necessary for cation exchange. Moreover, excess sodium ions $\left(\mathrm{Na}^{+}\right)$stimulate an increased production of pozzolanic compounds and are regarded as advantageous to the soil's silica dissolution. Moreover, the presence of sodium ions in solution is believed to compress a diffuse water layer, thereby increasing interparticle contact and aiding the flocculation process, which lead to formation of cementing materials due to chemical reactions (Davoudi and Kabir, 2011; Marks and Haliburton, 1999).

So far, there has been no evidential academic discourse on the impact of salts on the stress-strain behaviour of lime-treated organic soil using triaxial compression testing. Hence, an experimental study on the behaviour of lime-treated organic clay based on consolidated undrained $(\mathrm{CU})$ and consolidated drained (CD) triaxial tests with various sodium chloride contents $(0 \cdot 5,2 \cdot 0$ and $5.0 \%)$ and at curing periods of 7 and $28 \mathrm{~d}$ was carried out to consider the possible advantages of using additives or additional binders for enhancing the lime stabilisation process. A microstructural analysis (scanning electron microscopy (SEM) and X-ray diffraction (XRD)) was conducted to offer further insights and clarify the engineering test results on the particle level.

\section{Materials and specimen preparation}

The artificial organic clay used in this study was prepared by mixing a commercial kaolin with $1 \cdot 5 \%$ commercial humic acid according to the dry mass of kaolin. Humic acid is a well-known constituent of organic matter with the potential to disrupt the soil stabilisation process (Petry and Glazier, 2004). A mixture of $1.5 \%$ humic acid, at $5 \%$ optimum lime content, was prepared to be stabilised with various amounts of sodium chloride (Chen et al., 2009; Mohd Yunus et al., 2013a; Petry and Glazier, 2004). The salt was added to the limetreated organic clay in the amounts of $0 \cdot 5,2 \cdot 0$ and $5 \cdot 0 \%$. The results of index testing carried out on untreated specimens are summarised in Table 1. More details on the physical properties of the untreated organic clay can be found in the paper by Mohd Yunus et al. (2012).

The specimens tested in this study were prepared using the standard procedures described in ASTM D 5102-96 (ASTM, 2004). Initially, the specimens were oven-dried at $60^{\circ} \mathrm{C}$ until a constant weight was obtained. Untreated organic clay was prepared by mixing dry kaolin with $1.5 \%$ humic acid by dry mass of kaolin. Then, $5 \%$ of lime content and different amounts of sodium chloride were added to the predetermined amount of organic clay. Mixing of dry materials was continued until a uniform appearance of the soil mixture was obtained. Distilled water was then added according to the optimum moisture content $\left(O_{\mathrm{MC}}\right)$ of untreated organic clay, determined using the standard Proctor test (Mohd Yunus et al., 2012), and further mixing was performed until a homogeneous appearance of the soil paste was achieved. In this study, all of the specimens were compacted at similar densities and water contents as specified in Table 1 to perform comparable analysis.

The process of mixing was conducted as quickly as possible to ensure that lime was not exposed to air for too long. This was necessary to avoid the carbonation process that could affect the strength characteristics of lime-treated specimens. The specimens were compacted into the mould $(76 \mathrm{~mm}$ high and $38 \mathrm{~mm}$ in diameter) at a specified moisture content to achieve the specified dry density. A small amount of grease was applied inside the brass mould to minimise friction. The specimens were then extruded from the mould and wrapped in cling film to preserve the water content and to keep them free from carbon dioxide $\left(\mathrm{CO}_{2}\right)$. The specimens were then cured in desiccators at $20^{\circ} \mathrm{C}$ and with humidity more than $90 \%$ for 7 and $28 \mathrm{~d}$. A back pressure of $400 \mathrm{kPa}$ was applied to all the samples to ensure saturation of the soil. A specimen was regarded as sufficiently saturated when Skempton's $B$ value was greater than 0.95 for untreated soil and 0.90 for treated soil.

Table 1. Physical properties of clay with $1.5 \%$ humic acid content

$\begin{array}{lc}\text { Property } & \text { K1.5HA } \\ \text { Liquid limit: \% } & 63 \cdot 6 \\ \text { Plastic limit: \% } & 33 \cdot 8 \\ \text { Plasticity index: \% } & 29 \cdot 5 \\ \text { Specific gravity } & 2 \cdot 61 \\ \text { pH } & 5 \cdot 16 \\ O_{M C}: \% & 30 \cdot 6 \\ M_{D D}: \mathrm{kg} / \mathrm{m}^{3} & 1425\end{array}$

$\mathrm{K}$, kaolin; $\mathrm{HA}$, humic acid; $O_{M C}$, optimum moisture content; $M_{\mathrm{DD}}$, maximum dry density 


\section{Results and discussion}

The results of the CU and CD triaxial tests carried out on the stabilised clay specimens are presented in this paper based on a stress path analysis representing the successive states of stress during the shearing stage. The triaxial tests were conducted following 7 and $28 \mathrm{~d}$ of curing and were based on BS 13778:1990 (BSI, 1990). Effective confining pressures $\left(\sigma_{3}^{\prime}\right)$ of 50 and $100 \mathrm{kPa}$ were applied, respectively.

\section{Undrained behaviour}

The changes in the stress-strain behaviour of lime-treated organic clay due to the influence of sodium chloride content after $7 \mathrm{~d}$ of curing are presented in Figure 1. To begin with, an effective confining pressure $\left(\sigma_{3}^{\prime}\right)$ of $50 \mathrm{kPa}$ was applied. As shown in

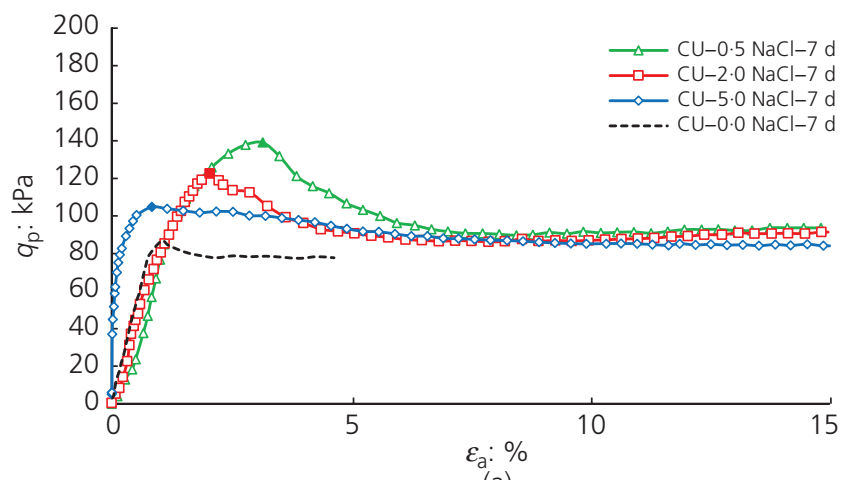

(a)

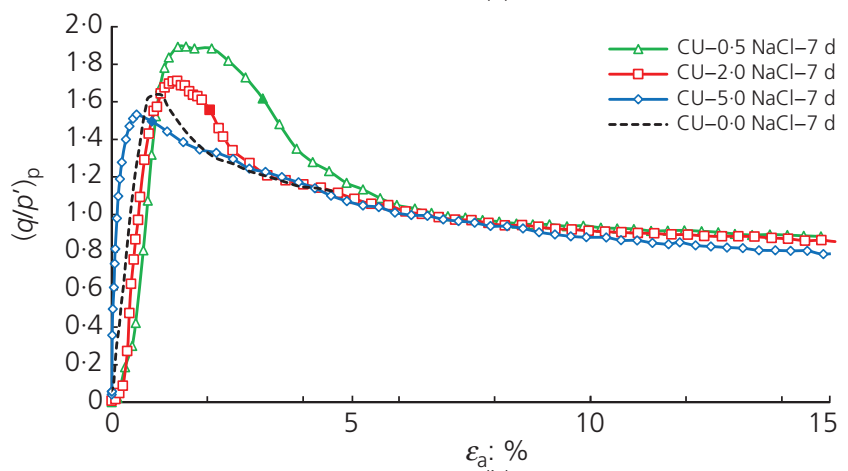

(b)

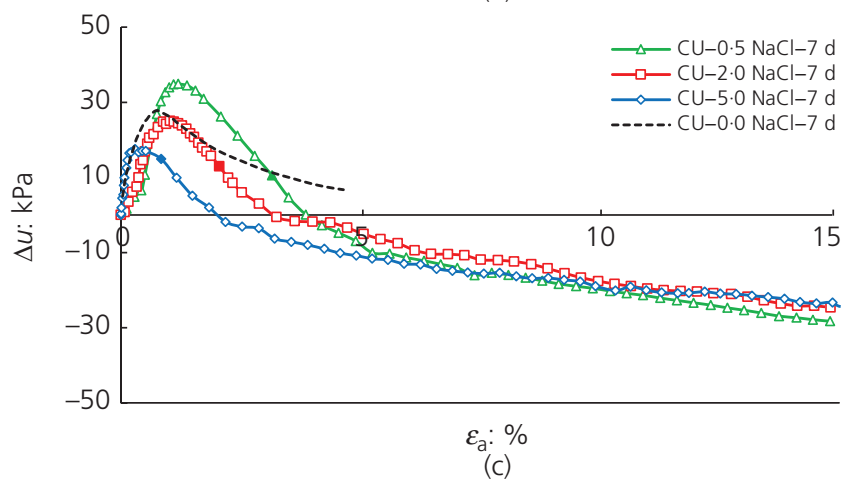

Figure 1. Effects of sodium chloride content on the undrained behaviour of lime-treated organic clay at $7 \mathrm{~d}$ of curing: (a) $q_{\mathrm{p}}-\varepsilon_{\mathrm{a}}$, (b) $\left(q / p^{\prime}\right)_{\mathrm{p}}-\varepsilon_{\mathrm{a}}$ and (c) $\Delta u-\varepsilon_{\mathrm{a}}$
Figure 1(a), it is observed that specimen failures occur at the peak deviator stresses $\left(q_{\mathrm{p}}\right)$ that correspond to relatively small axial strains in the range of $0 \cdot 5-3 \cdot 5 \%$. The specimen's failure in all the tests conducted was associated with shear band formation, which was in agreement with the tests carried out by Hebib and Farrell (2003) and Koslanant et al. (2006).

Figure 1(a) shows that, except for the lime-treated organic clay that contains $0.5 \%$ sodium chloride, a gradual decline in the deviator stress with increased strain is observed in the $q_{\mathrm{p}}$ values of all other specimens, until there is no further substantial change in the stress. These types of soils that demonstrate such behaviour at the maximum stress are considered to have endured strain softening.

It can be observed from Figure 1(a) that there is a decrease in the peak deviator stress $\left(q_{\mathrm{p}}\right)$ of specimens with an increase in the sodium chloride content. More precisely, there was a reduction in $q_{\mathrm{p}}$ from $139 \mathrm{kPa}(0.5 \%$ sodium chloride) to 123 and $105 \mathrm{kPa}$ for 2.0 and $5.0 \%$ sodium chloride, respectively, which indicates that $0.5 \%$ sodium chloride is considered as the optimum salt content $\left(O_{\mathrm{SC}}\right)$ to be stabilised with lime-treated soil. Despite observing a decrease in $q_{\mathrm{p}}$ at higher salt content, the $q_{\mathrm{p}}$ of each specimen treated with salt was still higher than the $q_{\mathrm{p}}$ of the specimens treated with only lime (depicted with black dashed lines in all the figures). It needs to be noted that the specimen without any salt contains $1.5 \%$ humic acid and is treated with $5 \%$ lime. Figure 1(a) shows that the $q_{\mathrm{p}}$ of the specimen with the lowest salt content ( $0.5 \%$ sodium chloride) was almost twice as large as the $q_{\mathrm{p}}$ of the specimen that had $0 \%$ salt content. The $q_{\mathrm{p}}$ value of lime-treated organic clay with $0 \cdot 5 \%$ sodium chloride was $139 \cdot 1 \mathrm{kPa}$, while the $q_{\mathrm{p}}$ of lime-treated organic clay without salt was only $86.6 \mathrm{kPa}$.

Figure 1(b) shows the influence of salt content on the peak effective stress ratio $\left(q / p^{\prime}\right)_{\mathrm{p}}$ for specimens stabilised with sodium chloride, The CU test results indicate that the peak $\left(q / p^{\prime}\right)_{\mathrm{p}}$ did not occur simultaneously with the $q_{\mathrm{p}}$. The $\left(q / p^{\prime}\right)_{\mathrm{p}}$ was reached marginally earlier than the $q_{\mathrm{p}}$, at about $0 \cdot 5-1 \cdot 5 \%$ axial strain. Differences in the positions of $\left(q / p^{\prime}\right)_{\mathrm{p}}$ and $q_{\mathrm{p}}$ were observed as a result of the variations in pore water pressure during shearing under undrained conditions (Figure 1(c)) and because $q_{\mathrm{p}}$ is not a function of pore water pressure. Figure $1(\mathrm{c})$ shows that $\left(q / p^{\prime}\right)_{\mathrm{p}}$ was reached at the same strains as the peaks of $\Delta u$. Figure 1(c) also illustrates the variations in excess pore water pressure $(\Delta u)$ during the course of undrained shearing for specimens with different levels of sodium chloride content. The rise in negative $\Delta u$ in specimens that were treated with decreasing salt content goes on to prove that an increase in the effective stress is consistent with the plots of $q_{\mathrm{p}}$ and $\left(q / p^{\prime}\right)_{\mathrm{p}}$ against $\varepsilon_{\mathrm{a}}$. It is thought that salt content exceeding $0 \cdot 5 \%$ may provide surplus cations, which in turn create an unbalance in the exchange activity of cations (Davoudi and Kabir, 2011; Kazemian et al., 2011). Subsequently, this deters the flocculation process that takes place in the early phases of stabilisation. On the whole, the results derived from the $\mathrm{CU}$ triaxial tests demonstrate the efficacy of salt addition in increasing the strength of limetreated specimens in just $7 \mathrm{~d}$ of curing. 
The behaviour of lime-treated organic clay that contains different amounts of sodium chloride after $28 \mathrm{~d}$ of curing is presented in Figure 2. Figure 2(a) shows that the $q_{\mathrm{p}}-\varepsilon_{\mathrm{a}}$ curves of the lime-treated specimens with the addition of chloride salt were considerably different from those of the specimens without any salt (shown with a black dashed line). Despite a noticeable reduction in the deviator stress after longer curing periods of the lime-treated organic clay (Mohd Yunus et al., 2012, 2013a, 2013b, 2014; Thangavel et al., 2010), the addition of salt resulted in considerable improvement of the specimens. The observation made after $7 \mathrm{~d}$ of curing showed a similar outcome, where $q_{\mathrm{p}}$ increased as the salt content decreased. This indicates that with the addition of small amounts of salt, it is feasible to attain effective stabilisation of lime-treated clay specimens that have $1 \cdot 5 \%$ humic acid content. Compared to the $q_{\mathrm{p}}$ of specimens with $0 \%$ salt content, the $q_{\mathrm{p}}$ of specimens with salt are three to four

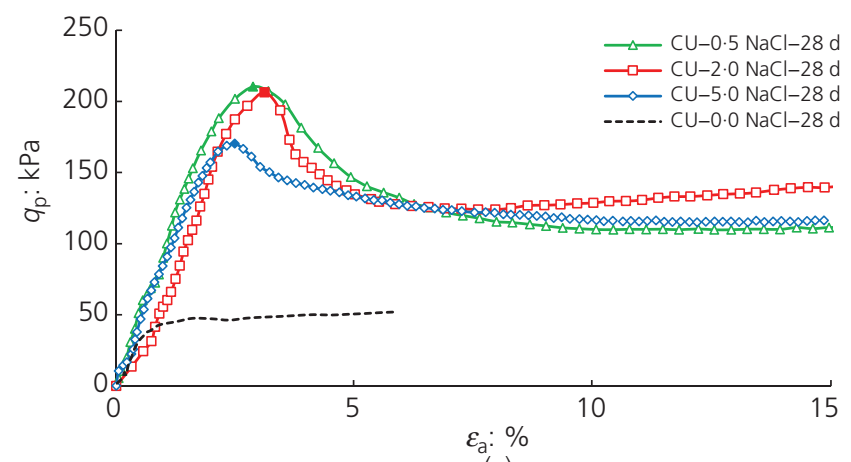

(a)

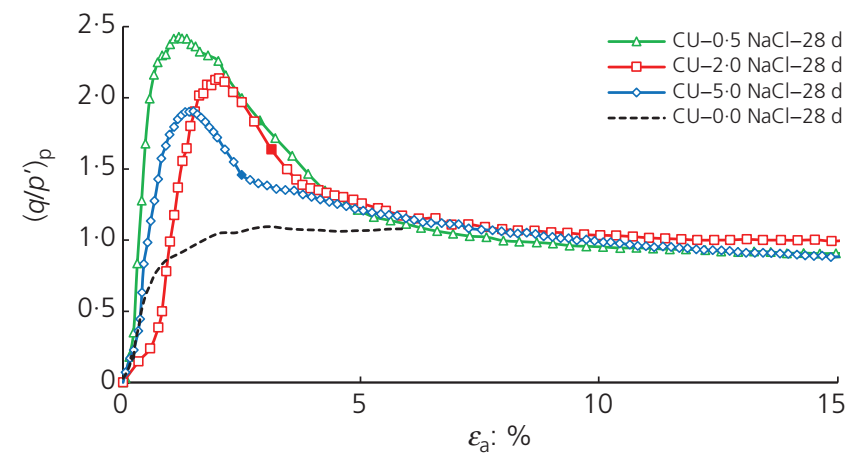

(b)

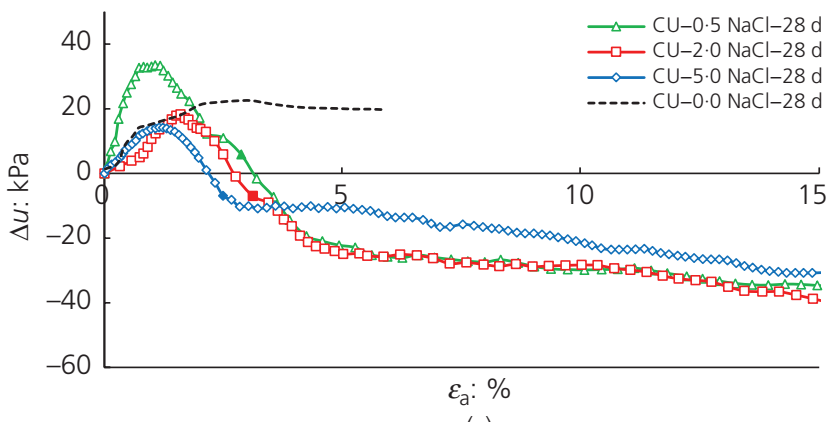

(c)

Figure 2. Effects of sodium chloride content on the undrained behaviour of lime-treated organic clay at $28 \mathrm{~d}$ of curing: (a) $q_{\mathrm{p}}-\varepsilon_{\mathrm{a}}$, (b) $\left(q / p^{\prime}\right)_{p}-\varepsilon_{a}$ and (c) $\Delta u-\varepsilon_{a}$ times higher. For example, the $q_{\mathrm{p}}$ of lime-treated organic clay with $0.5 \%$ sodium chloride was $210.3 \mathrm{kPa}$, while the $q_{\mathrm{p}}$ of the limetreated organic clay without salt was only $47.6 \mathrm{kPa}$. It is hypothesised that the improvement in clay behaviour due to the addition of the salt was achieved because of the initial effect of $5 \%$ lime content that stimulated the dispersion of calcium $\left(\mathrm{Ca}^{2+}\right)$ ions, which in turn had an important role to play in the flocculation and pozzolanic reaction processes. Moreover, the addition of $0.5 \%$ sodium chloride resulted in supplementary contact that helped in modifying the chemical reaction between sodium ions and clay minerals. Although at this phase, the impact of various curing periods has not been evaluated, the current observations validate the benefits of adding salt to the lime-treated organic clay in the long term.

Figure 2(b) shows that similar to the $q_{\mathrm{p}}-\varepsilon_{\mathrm{a}}$ curves, the $\left(q / p^{\prime}\right)_{\mathrm{p}}$ values of the lime-treated organic clay, with different levels of sodium chloride content, increase after $28 \mathrm{~d}$ of curing as the salt content decreases. Also, it has to be mentioned that $\left(q / p^{\prime}\right)_{\mathrm{p}}$ attained its maximum value a little before the peak deviator stress. Moreover, as shown in Figure 2(c), the negative $\Delta u$ increased as the salt content decreased, which in turn implies increase in the effective stresses.

\section{Drained behaviour}

The stress-strain behaviours of the lime-treated organic clay specimens with a range of sodium chloride contents and sheared under drained environments were tested immediately after 7 and $28 \mathrm{~d}$ of curing to make sure that there is valid comparability with the $\mathrm{CU}$ tests. Figure 3 presents the impact of adding varying amounts of sodium chloride to lime-treated clay with $1.5 \%$ humic acid content after $7 \mathrm{~d}$ of curing. Moreover, the improvement in the properties of the clay attained by adding chloride salt was compared with the results of the tests carried out on the specimens treated with lime alone, and the outcomes are illustrated with dashed lines. It was observed that the failure of specimens occurred at the peak deviator stress $\left(q_{\mathrm{p}}\right)$. Figure 3(a) shows that the $q_{\mathrm{p}}$ for the specimens with salt was attained at axial strains in the range of $1 \cdot 5-5 \cdot 0 \%$. The $q_{\mathrm{p}}$ in the $\mathrm{CD}$ tests, similar to that in the CU tests, decreased as the salt content increased. The $q_{\mathrm{p}}$ decreased from 153 to $142 \mathrm{kPa}$ (for $0.5 \%$ sodium chloride) and $116 \mathrm{kPa}$ (for $2 \cdot 0$ and $5 \cdot 0 \%$ sodium chloride). Also, it was noticed that the $q_{\mathrm{p}}$ for all the specimens treated with chloride salt was higher than that of the specimens treated with $5 \%$ lime alone (that is, $q_{\mathrm{p}}=106 \mathrm{kPa}$ ). This implies that the addition of salt effectively altered the characteristics of the lime-treated clay that contains $1 \cdot 5 \%$ humic acid. Figure 3 (b) shows the impact of sodium chloride on the effective stress ratio $\left(q / p^{\prime}\right)_{\mathrm{p}}$. The results of the $\mathrm{CD}$ test indicate that $\left(q / p^{\prime}\right)_{\mathrm{p}}$ is attained at the same $\varepsilon_{\mathrm{a}}$ as the $q_{\mathrm{p}}$. Figure 3(c) presents the variation in volumetric strain $\left(\varepsilon_{\mathrm{v}}\right)$ with axial strain $\left(\varepsilon_{\mathrm{a}}\right)$ for lime-treated specimens with sodium chloride content after $7 \mathrm{~d}$ of curing. Compared to the specimens with $0 \%$ sodium chloride, the specimens with chloride salt demonstrated an increase in the dilative behaviour at large axial strain, with an increase in the magnitude of dilation, as the salt content decreased.

It is necessary to note at this stage that the dilative behaviour has a substantial positive impact on the shear strength of the soil (e.g. 
Strength improvement of lime-treated

clay with sodium chloride

Mohd Yunus, Wanatowski, Marto and Jusoh

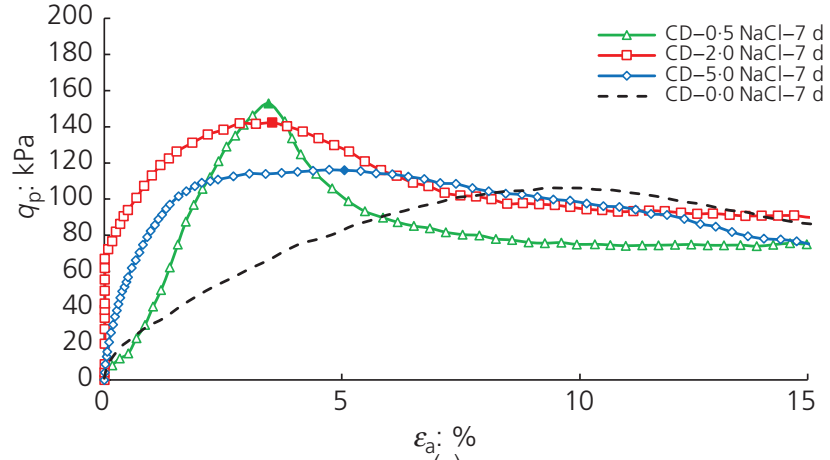

(a)

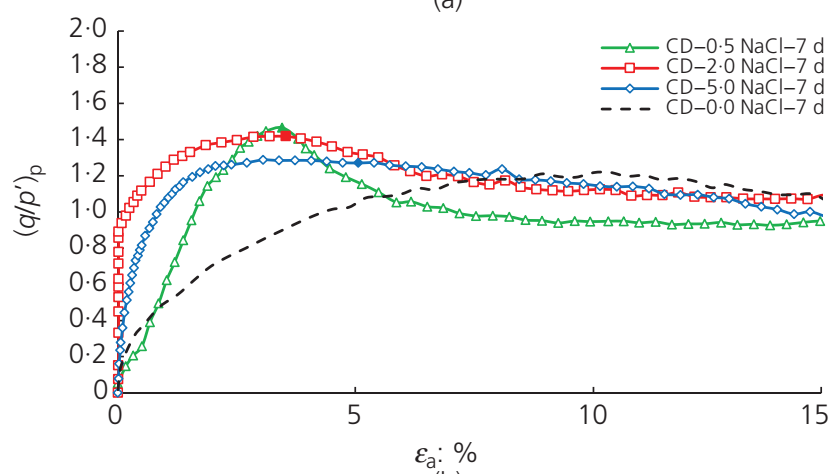

(b)

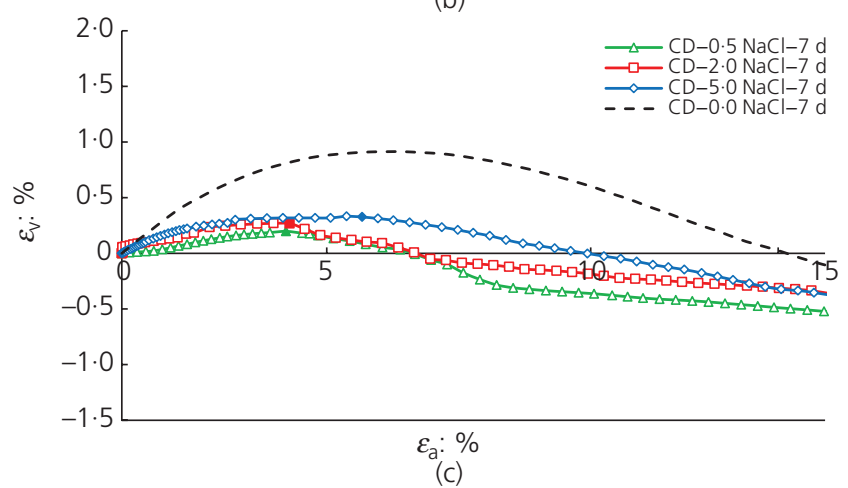

Figure 3. Effects of sodium chloride content on the drained behaviour of lime-treated organic clay at $7 \mathrm{~d}$ of curing: (a) $q_{\mathrm{p}}-\varepsilon_{\mathrm{a}}$, (b) $\left(q / p^{\prime}\right)_{\mathrm{p}}-\varepsilon_{\mathrm{a}}$ and (c) $\varepsilon_{\mathrm{v}}-\varepsilon_{\mathrm{a}}$

Chu et al., 2015; Lade and Trads, 2014; Likitlersuang et al., 2014). This suggests that the tendency of lime-treated specimens containing salt to exhibit a dilative behaviour during drained loading results in an increase in the soil's shear strength within $7 \mathrm{~d}$ of curing.

Figure 4 illustrates the impact of sodium chloride on the stress-strain behaviour of lime-treated clay with $1.5 \%$ humic acid after $28 \mathrm{~d}$ of curing. It is evident from Figure 4 (a) that the $q_{\mathrm{p}}$ values of all specimens that contain chloride salt were significantly higher than those of the specimens without salt. According to the test results, there was a considerable increase in strength, between 147 and $450 \%$, from the $q_{\mathrm{p}}$ value of the specimen without salt, which was only $83 \mathrm{kPa}$. The specimens with $0 \cdot 5 \%$ sodium chloride
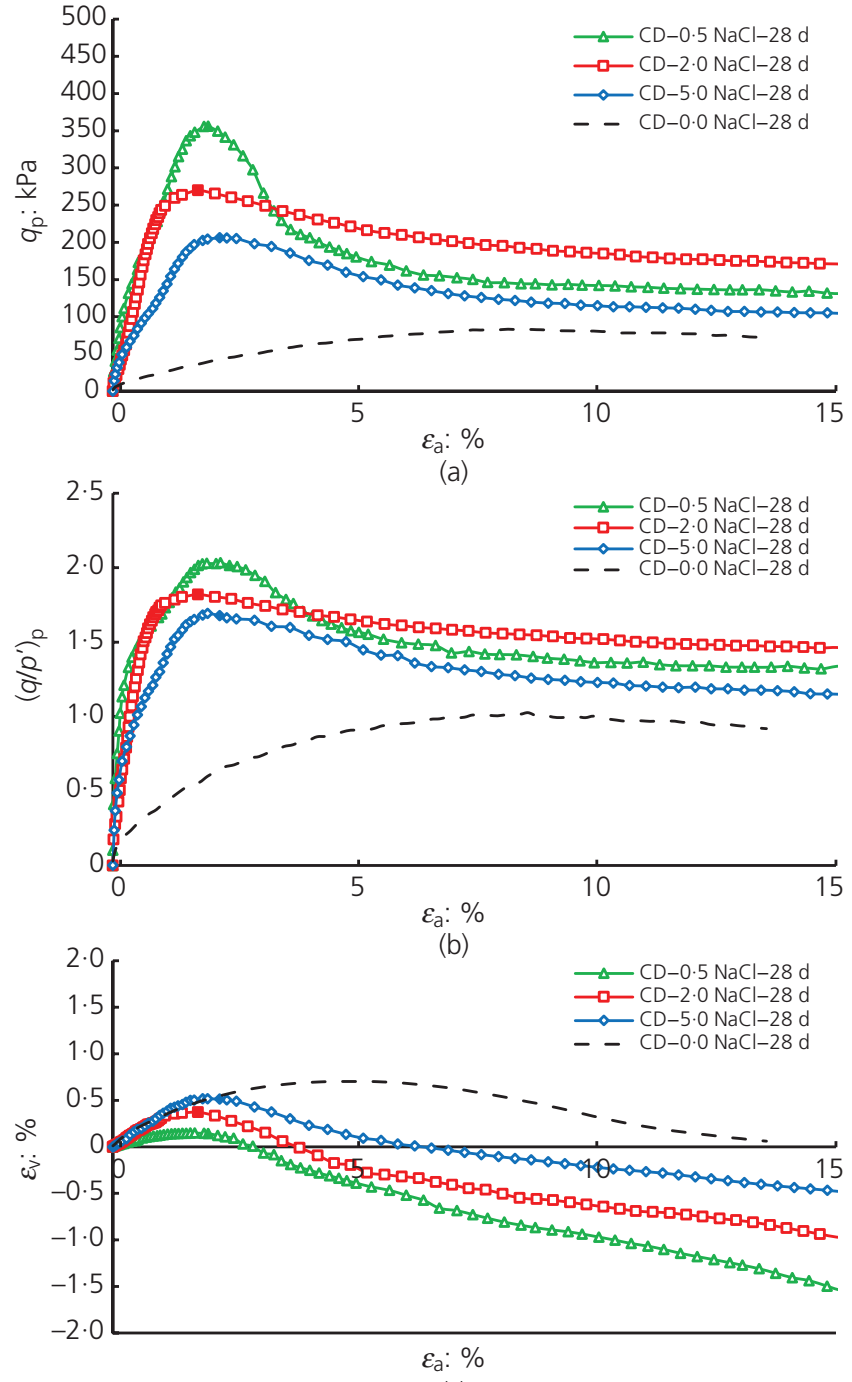

(c)

Figure 4. Effects of sodium chloride content on the drained behaviour of lime-treated organic clay at $28 \mathrm{~d}$ of curing: (a) $q_{\mathrm{p}}-\varepsilon_{\mathrm{a}}$, (b) $\left(q / p^{\prime}\right)_{p}-\varepsilon_{a}$ and $(c) \varepsilon_{v}-\varepsilon_{a}$

exhibited the highest $q_{\mathrm{p}}$, corresponding to $356 \mathrm{kPa}$. The behaviour resembled the observation after $7 \mathrm{~d}$ of curing (Figure 1(a)), and in this case as well, the $q_{\mathrm{p}}$ was noted to decrease as the salt content increased. Figure 4(b) illustrates the influence of salt content on the peak effective stress ratio $\left(q / p^{\prime}\right)_{\mathrm{p}}$ after $28 \mathrm{~d}$ of curing. It can be concluded from the test results that the $\left(q / p^{\prime}\right)_{\mathrm{p}}$ values of specimens with salt were much higher than those of the specimens without any salt. There is a consistent relationship between a high $\left(q / p^{\prime}\right)_{\mathrm{p}}$ and a low level of chloride salt. Figure 4(c) presents the change in the volumetric strains $\left(\varepsilon_{\mathrm{v}}\right)$ of specimens with chloride salt measured at $28 \mathrm{~d}$ of curing. It has been observed that for specimens containing chloride salt, the amount of dilation increases as the salt content decreases. As mentioned earlier, the dilative behaviour of soil is linked with high shear strength. Therefore, it can be concluded that the specimens with low salt content $(0 \cdot 5 \%$ sodium 
chloride) are characterised by a higher shear strength. This is discussed in detail in the next section.

\section{Comparison between CU and CD triaxial tests}

Figure 5 presents the effective stress paths of lime-treated organic clay containing $0.5 \%$ sodium chloride. A comparison was made between the effective failure parameters calculated from the $\mathrm{CU}$ and CD tests. The peak effective stress states, derived from each effective stress path, were connected to determine the resulting failure lines. Figure 5 shows the impact of adding $0.5 \%$ sodium chloride on the $q-p^{\prime}$ plot that was assessed based on the specimens without lime content. Figure 5 shows that the stress paths of the CU samples led to the same failure envelopes as that of the $\mathrm{CD}$ samples. This outcome reveals that the failure parameters derived from the $\mathrm{CU}$ and $\mathrm{CD}$ tests were consistent. Moreover, the equations given in Figure 5 show that the slopes of failure line determined for the specimens containing chloride salt were steeper than those without any salt content.

The effective shear strength parameters $\left(c^{\prime}\right.$ and $\left.\phi_{\mathrm{p}}^{\prime}\right)$ were also determined for the lime-treated specimens containing $0.5 \%$ sodium chloride. With the help of Equations 1 and 2, the values for $c^{\prime}$ and $\phi_{\mathrm{p}}^{\prime}$ were calculated.

1. $\phi_{\mathrm{p}}^{\prime}=\sin ^{-1}[3 m /(6+m)]$

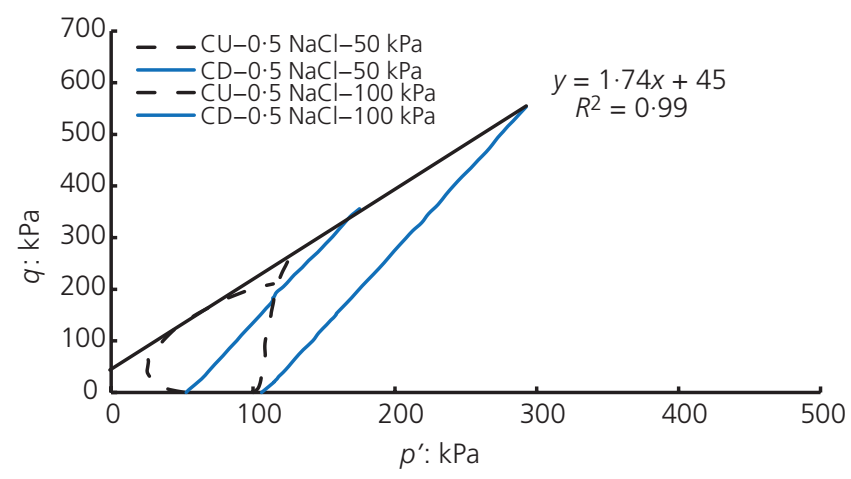

Figure 5. Stress paths and failure envelope of organic clay treated with $5 \%$ lime and $0.5 \%$ sodium chloride

\section{2. $c^{\prime}=\left(a \tan \phi^{\prime}\right) / m$}

where $m$ is the gradient of slope $/\left(q / p^{\prime}\right)_{\mathrm{p}} ; \phi^{\prime}$ is the effective friction angle; $q$ is the deviator stress $\left(\sigma_{1}-\sigma_{3}\right) ; p^{\prime}$ is the mean effective stress $\left(1 / 3\left(\sigma_{1}+2 \sigma_{3}\right)\right) ; a$ is the intercept at $y$-axis; $\sigma_{1}$ is the major principal stress; and $\sigma_{3}$ is the minor principal stress.

For samples containing $0 \cdot 5 \%$ sodium chloride, the calculated $c^{\prime}$ value was equal to $23.6 \mathrm{kPa}$. This value is significantly higher than the value for the samples without any salt $(0 \%$ sodium chloride), where $c^{\prime}$ was about $7 \cdot 1 \mathrm{kPa}$. Moreover, the $\phi_{\mathrm{p}}^{\prime}$ of the lime-treated specimen with $1.5 \%$ humic acid increased substantially from $20.7^{\circ}$ for $0 \%$ sodium chloride to $42 \cdot 4^{\circ}$ for $0 \cdot 5 \%$ sodium chloride. The increased values of $c^{\prime}$ and $\phi_{\mathrm{p}}^{\prime}$ confirm that the effective shear strength of organic clay can be successfully improved by the addition of a small amount of sodium chloride, which in this particular case is $0.5 \%$. Furthermore, the triaxial test results clearly show that the shear strengths of lime-treated clay specimens, containing $1.5 \%$ humic acid, increase on addition of $0.5 \%$ sodium chloride.

In addition to the strength tests, the compressibility behaviour of lime-treated organic clay with varying amounts of sodium chloride was studied at $7 \mathrm{~d}$ of curing. As with the strength tests, all of the specimens were prepared with $1.5 \%$ humic acid and $5 \%$ lime content. Furthermore, each specimen had an initial water content of $63 \%$, corresponding to the liquid limit of lime-treated clay containing $1.5 \%$ humic acid. Tables 2 and 3 provide the initial properties of the lime-treated organic clay without and with addition of sodium chloride, after 7 and $28 \mathrm{~d}$ of curing, respectively. Table 2 also shows initial void ratios $\left(e_{\mathrm{i}}\right)$ of specimens varying from 1.47 to 1.58 . The variation in $e_{\mathrm{i}}$ is due to the changes in water content. It can be seen from Table 2 that the initial water contents of the cured specimens to which the chloride salt had been added were noticeably lower than those without salt. The difference in the water content is observed due to a more effective hydration process that had occurred during curing after salt was introduced. Similar observations were reported by Chen and Wang (2006).

Figure 6 shows the compression curves of lime-treated specimens containing sodium chloride after $7 \mathrm{~d}$ of curing. It shows the impact

Table 2. Summary of oedometer test results on lime-treated organic clay with varying amounts of sodium chloride after $7 \mathrm{~d}$ of curing

\begin{tabular}{|c|c|c|c|c|}
\hline & \multicolumn{4}{|c|}{ Specimen } \\
\hline & $0 \%$ Sodium chloride & $0.5 \%$ Sodium chloride & $2.0 \%$ Sodium chloride & $5.0 \%$ Sodium chloride \\
\hline Diameter: mm & 75 & 75 & 75 & 75 \\
\hline Height: mm & $19 \cdot 2$ & $19 \cdot 2$ & $19 \cdot 2$ & $19 \cdot 2$ \\
\hline Initial water content $w_{\mathrm{i}}: \%$ & $62 \cdot 9$ & $58 \cdot 6$ & $59 \cdot 4$ & $60 \cdot 2$ \\
\hline Initial void ratio $e_{i}$ & $1 \cdot 58$ & 1.47 & 1.49 & 1.51 \\
\hline Compression index $C_{c}$ & $0 \cdot 33$ & 0.24 & $0 \cdot 31$ & $0 \cdot 37$ \\
\hline Pre-consolidation stress $p_{c}^{\prime}: \mathrm{kPa}$ & 115 & 125 & 120 & 80 \\
\hline Overconsolidation ratio $\left(p_{\circ}^{\prime}=50 \mathrm{kPa}\right)$ & $2 \cdot 3$ & $2 \cdot 5$ & $2 \cdot 4$ & $1 \cdot 6$ \\
\hline Overconsolidation ratio $\left(p_{0}^{\prime}=100 \mathrm{kPa}\right)$ & $1 \cdot 15$ & $1 \cdot 25$ & $1 \cdot 2$ & 0.8 \\
\hline
\end{tabular}


Table 3. Summary of oedometer test results on lime-treated organic clay with varying amounts of sodium chloride after $28 \mathrm{~d}$ of curing

\begin{tabular}{|c|c|c|c|c|}
\hline & \multicolumn{4}{|c|}{ Specimen } \\
\hline & $0 \%$ Sodium chloride & $0.5 \%$ Sodium chloride & $2 \cdot 0 \%$ Sodium chloride & $5.0 \%$ Sodium chloride \\
\hline Diameter: mm & 75 & 75 & 75 & 75 \\
\hline Height: mm & $19 \cdot 2$ & $19 \cdot 2$ & $19 \cdot 2$ & $19 \cdot 2$ \\
\hline Initial water content $w_{i}: \%$ & $60 \cdot 6$ & $56 \cdot 6$ & 57 & $58 \cdot 2$ \\
\hline Initial void ratio $e_{i}$ & 1.52 & $1 \cdot 42$ & 1.43 & $1 \cdot 46$ \\
\hline Compression index $C_{c}$ & 0.34 & 0.22 & 0.26 & $0 \cdot 31$ \\
\hline Pre-consolidation stress $p_{c}^{\prime}: \mathrm{kPa}$ & 80 & 140 & 130 & 121 \\
\hline Overconsolidation ratio $\left(p_{0}^{\prime}=50 \mathrm{kPa}\right)$ & $1 \cdot 6$ & $2 \cdot 8$ & $2 \cdot 6$ & $2 \cdot 42$ \\
\hline Overconsolidation ratio $\left(p_{\circ}^{\prime}=100 \mathrm{kPa}\right)$ & 0.8 & 1.4 & $1 \cdot 3$ & $1 \cdot 21$ \\
\hline
\end{tabular}

that different amounts of sodium chloride have on the void ratios of the lime-treated specimens. It can be seen that the $\varepsilon_{\mathrm{v}}$ of the specimens with $0 \cdot 5$ and $2 \cdot 0 \%$ sodium chloride decreases much less compared to the $\varepsilon_{\mathrm{v}}$ of the specimens without salt. However, Figure 6 shows that the lime-treated specimens with $5 \%$ sodium chloride have undergone significantly more compression than those without salt despite having reduced void ratios at the beginning of compression. Such behaviour indicates that the properties of salt-treated specimens after $7 \mathrm{~d}$ of curing improved with the addition of up to $2 \%$ sodium chloride. Further addition of sodium chloride does not improve the compression behaviour of lime-treated clay.

The compression results are also consistent with the strength tests where the optimum salt content $\left(O_{\mathrm{SC}}=0.5 \%\right)$ was determined. Any further addition of chloride salt beyond $O_{\mathrm{SC}}=0.5 \%$ did not contribute towards improving the strength properties of limetreated organic clay. The earlier-mentioned reduction in the void ratio and the consequent improvement in the soil structure support the results of previously reported triaxial tests conducted on similar specimens cured for the same period of time. Therefore, the results obtained from both types of tests suggest that the reduction in the void ratio of the salt-treated specimens was caused by the formation of cementitious products (i.e. calcium silicate hydrate $(\mathrm{CSH})$ and calcium aluminate hydrate $(\mathrm{CAH})$ ), which subsequently occupied the voids within the soil structure (Boardman et al., 2001; Choquette et al., 1987; James et al.,

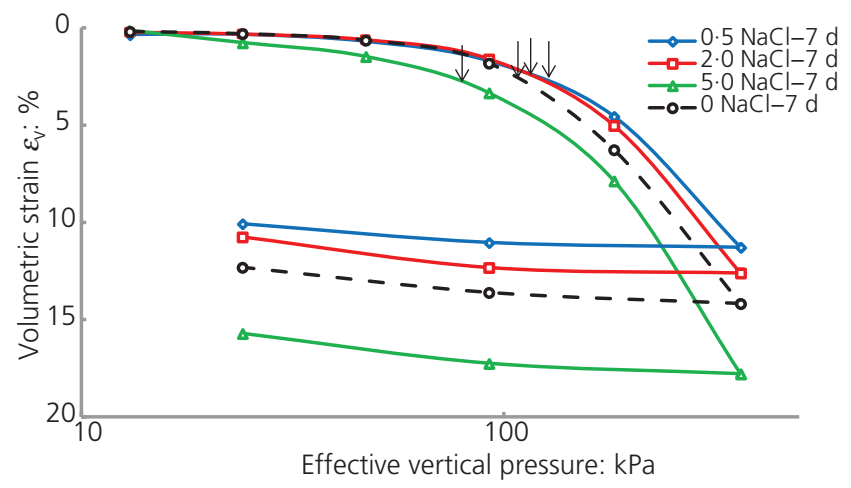

Figure 6. Effect of sodium chloride on the compression behaviour of lime-treated organic clay after $7 \mathrm{~d}$ of curing
2008; Rajasekaran and Rao, 1997). The change in structure, in turn, resulted in the increase in shear strength and the reduction in the compressibility of the lime-treated organic clay.

The effect of adding sodium chloride can be further examined by estimating the preconsolidation pressure, $p_{\mathrm{c}}^{\prime}$, based on Casagrande's method, as shown in Figure 6. The $p_{\mathrm{c}}^{\prime}$ values (indicated by the arrows on the compression curves) of 125 and $120 \mathrm{kPa}$ were determined for the lime-treated specimens with 0.5 and $2.0 \%$ sodium chloride, respectively. Both $p_{\mathrm{c}}^{\prime}$ values were larger than the $p_{\mathrm{c}}^{\prime}=$ $115 \mathrm{kPa}$ measured for the specimen with $0 \%$ sodium chloride. In contrast, the value of $p_{\mathrm{c}}^{\prime}$ reduced from $115 \mathrm{kPa}$ for the $0 \%$ sodium chloride specimen to $80 \mathrm{kPa}$ when $5.0 \%$ sodium chloride was introduced to the lime-treated specimen. Furthermore, the effect of adding sodium chloride to the lime-treated clay containing $1.5 \%$ humic acid can be explained by comparing the compression indices, $C_{\mathrm{c}}$, necessary to predict the amount of primary consolidation settlement. It was recorded that $C_{\mathrm{c}}$ decreased substantially when sodium chloride increased from 0 to $0 \cdot 5 \%$, which explains why the resistance of lime-treated organic clays to compression improved considerably. For instance, $C_{\mathrm{c}}$ decreases from 0.33 for the limetreated organic clay without salt to 0.24 for the lime-treated organic clay with $0.5 \%$ sodium chloride. In addition, the magnitude of $C_{\mathrm{c}}$ for 0.5 and $2.0 \%$ sodium chloride increased from about 0.24 to 0.31 . A further increase in $C_{\mathrm{c}}$ was reported at higher sodium chloride (i.e. $5.0 \%$ ), for which the magnitude of $C_{\mathrm{c}}=0.37$ was higher than that of the specimen without salt. Based on these results, it is evident that after $7 \mathrm{~d}$ of curing, only the specimens containing 0.5 and $2.0 \%$ chloride salt improved the compressibility behaviour of the organic lime-treated organic clay with $1 \cdot 5 \%$ humic acid content.

As mentioned previously, due to the presence of salt, the formation of cementitious compounds is enhanced, which in turn decreases the pore space within the accumulation, thus reducing the void ratio. As the voids get filled with cementing materials within the soil phase, the specimen expands outwards during shearing, causing an increase in volume (i.e. volumetric dilation).

\section{Microstructural analysis}

SEM and XRD analyses were used to study and record the changes in the soil composition and microstructure of selected specimens of lime-treated organic clay containing added salt. In 
Strength improvement of lime-treated

clay with sodium chloride

Mohd Yunus, Wanatowski, Marto and Jusoh

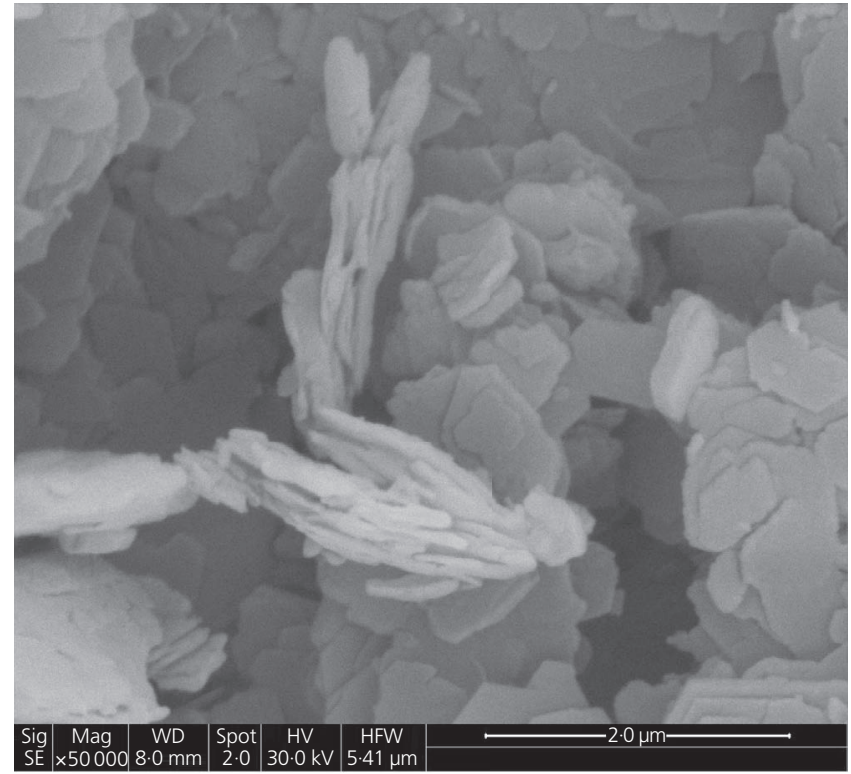

Figure 7. Soil structure of lime-treated organic clay without addition of sodium chloride

SEM analysis, a secondary electron was used to create the images that enabled the examination of the shape of the soil surface. In previous studies, the alterations in the soil structure as a result of lime stabilisation were visible only through aggregation and flocculation, while the effect on cementation was barely detectable in the SEM images (Al-Mukhtar et al., 2010; Kang et al., 2015, 2017; Mohd Yunus et al., 2013b, 2014, 2015; Petry and Glazier, 2004; Rajasekaran and Rao, 1997; Sakr and Shahin, 2009).

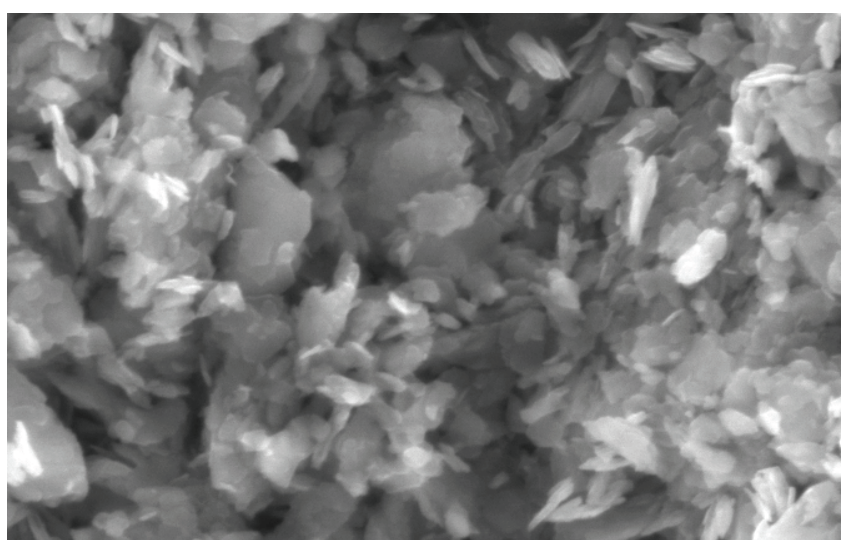

(a)
Similar observations were made in the present study. The aggregation and flocculation of clay structure could be observed in the SEM images, as shown in Figure 7. However, the occurrence of cementation products, such as $\mathrm{CAH}$ and $\mathrm{CSH}$, in the lime-stabilised organic clay without salt was only evident from the XRD analysis.

Figure 7 presents the micrograph of the organic clay containing $1.5 \%$ humic acid and treated with $5 \%$ lime (i.e. at the optimum lime content) after $28 \mathrm{~d}$ of curing. The stabilisation process typically takes place over the $28 \mathrm{~d}$ of curing. At this phase, it is expected that the cementation products such as $\mathrm{CAH}$ and $\mathrm{CSH}$ have developed in the soil structure. However, the SEM image could not identify the cementing structure of $\mathrm{CAH}$ or CSH. The voids in the structure can be seen within the aggregates of the lime-treated organic clay without any salt content, which in turn explains the shear strength reduction (Mohd Yunus et al., 2011, 2012).

Figure 8 presents the SEM images of lime-treated organic clay with $0.5 \%$ sodium chloride at two different magnifications of $\times 5000$ (Figure $8(a)$ ) and $\times 50000$ (Figure $8(b)$ ). As shown in Figures 8(a) and 8(b), the occurrence of cementation within the structure of the soil was evident when the lime-treated samples were stabilised with the addition of sodium chloride. In particular, a closer look at the structure shown in Figure 8(b) $(\times 50000$ magnification) reveals that the plate-like flaky structure, typical of the untreated soil, shown in Figure 7 ( $\times 50000$ magnification), was nearly absent. The cementing materials, primarily CSHs, were detected as a fine tubular and a well-knit structure (a needlelike form) that bridged the aggregates together. Choquette et al.

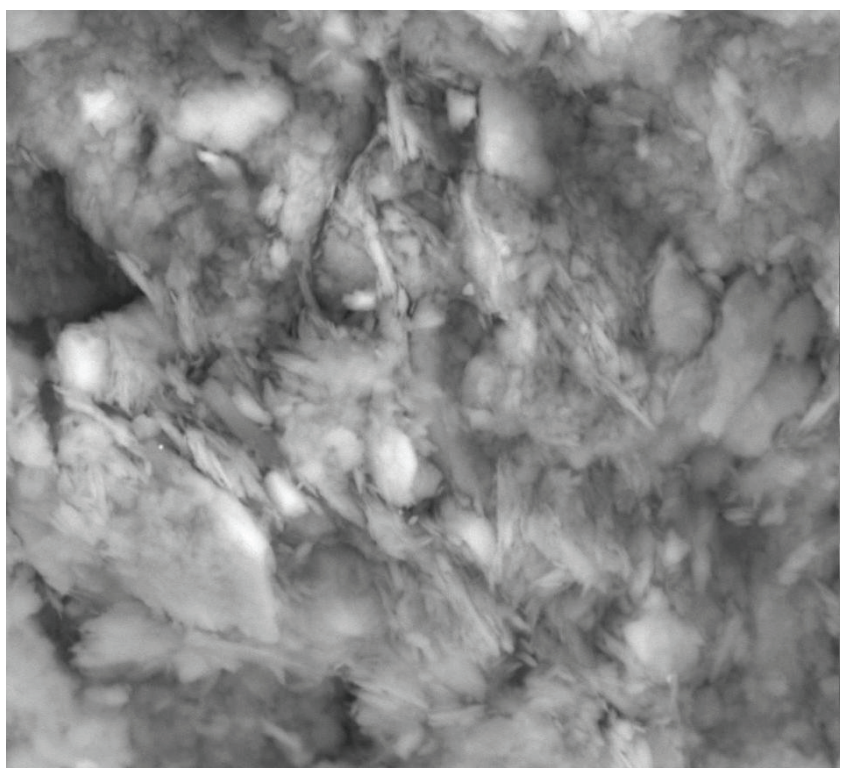

(b)

Figure 8. SEM images of a lime-treated sample with addition of $0.5 \%$ sodium chloride at $28 \mathrm{~d}$ of curing (a) $\times 5000$ magnification; (b) $\times 50000$ magnification 
(1987), James et al. (2008), Koslanant et al. (2006), Modmoltin and Voottipruex (2009), Onitsuka et al. (2001) and Rajasekaran and Rao (1997) also observed similar fine tubular and well-knit structures in their SEM studies. It should be noted, however, that the low-magnification image $(\times 5000)$, shown in Figure $8(a)$, revealed the appearance of a dispersed structure without a clear evidence of cementation within the soil's structure. This suggests that high-magnification SEM images are more useful for analysing the structure of cementitious materials.

Besides the SEM analysis, the occurrence of cementing materials within the soil's structure was further substantiated with the help of an XRD analysis on replicates of specimens after $28 \mathrm{~d}$ of curing that underwent unconfined compressive strength testing (Mohd Yunus et al., 2012). Figure 9 presents a typical XRD analysis of lime-treated organic specimens containing sodium chloride. In the XRD analysis, the cementing compounds in the soil specimens were detected by passing a known wavelength through the sample and by studying the diffraction of the wavelength by the crystal lattice that created a distinctive pattern of peaks of reflection with varying intensities and angles. Using the XRD analysis, the presence of $\mathrm{CSH}$ was detected at a $d$ spacing of 3.04 in the diffraction pattern and two diffraction angles $(2 \theta)$ of $26.9^{\circ}$ for all the specimens (including those with $0 \%$ sodium chloride) and $29 \cdot 355^{\circ}$ for the lime-treated organic clay with various sodium chloride contents. Despite this, the related diffraction angle created by the $\mathrm{CAH}$ compounds overlapped with that of the other minerals, which increased the possibility of inaccurate identification of the compounds. As a result of this limitation, only the presence of the CSH compound is reported in this study.

\section{Conclusions}

In this study, an additional binder was introduced to organic clay in order to improve the deficiencies of the lime stabilisation process. Sodium chloride was used in conjunction with limetreated organic clay containing $1.5 \%$ humic acid. Sodium chloride

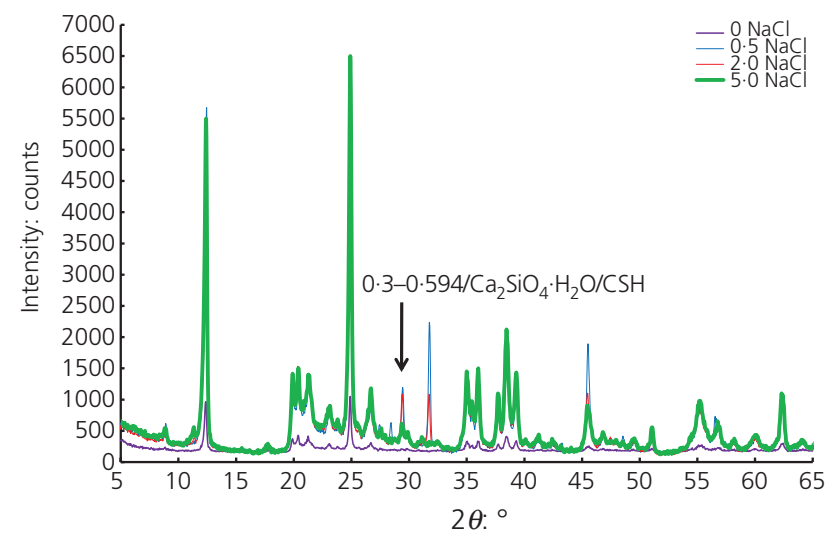

Figure 9. Diffraction pattern of lime-treated organic clay with various sodium chloride contents was introduced in the amounts of $0.5,2.0$ and $5.0 \%$. The influence of sodium chloride content on the drained and undrained behaviours of lime-treated organic clay can be summarised as follows.

v The triaxial test results presented in this paper validated the effectiveness of adding sodium chloride, which leads to an increase in the negative excess pore water pressure $(\Delta u)$ and dilative behaviour, ultimately resulting in the enhanced effective strength parameters of organic clay.

- The $c^{\prime}$ value determined for samples containing $0 \cdot 5 \%$ sodium chloride was equal to $23.6 \mathrm{kPa}$, which was significantly higher than the value $(=7 \cdot 1 \mathrm{kPa})$ determined for the samples without any salt ( $0 \%$ sodium chloride). Furthermore, the $\phi_{\mathrm{p}}^{\prime}$ of the lime-treated specimens with $1.5 \%$ humic acid increased substantially from $20 \cdot 7^{\circ}$ for $0 \%$ sodium chloride to $42 \cdot 4^{\circ}$ for $0 \cdot 5 \%$ sodium chloride.

- The optimum salt content $\left(O_{\mathrm{SC}}\right)$ was determined based on the highest increase in the strength obtained beyond which a decrease in strength was noted. In this study, the behaviour of lime-treated organic clay with addition of sodium chloride indicates that the $O_{\mathrm{SC}}$ obtained for the tested clay was equal to $0 \cdot 5 \%$ sodium chloride. It should be noted that the $O_{\mathrm{SC}}$ determined was within the range of salt contents used in this study. The consideration of $O_{\mathrm{SC}}$ for the lowest amount of salt capable of enhancing the shear strength of clay is always beneficial from an economic and environmental perspective.

- The microstructural analysis conducted in this study showed that the addition of sodium chloride to lime-treated organic clay improved the formation of cementing compounds. The SEM analysis confirmed the same for specimens with $0.5 \%$ sodium chloride after $28 \mathrm{~d}$ of curing. Moreover, the XRD analysis helped in identifying more areas of high $\mathrm{CSH}$ intensity in the sodium chloride-treated specimens in comparison to the specimens without any salt additives.

\section{Acknowledgements}

The authors gratefully acknowledge the financial support and contribution given by the Ministry of Education through Universiti Teknologi Malaysia under the Research University Grant Scheme (GUP-Tier 1 - VOT NO 15H34).

The second author would also like to acknowledge the financial support from the National Natural Science Foundation of China (Grant Number 51408326).

\section{REFERENCES}

Abood TT, Kasa A and Chik Z (2007) Stabilisation of silty clay using chloride compounds. Journal of Engineering Science and Technology 2(1): $102-110$.

Ahnberg H (2004) Effects of back pressure and strain rate used in triaxial testing of stabilized organic soils and clays. Geotechnical Testing Journal 27(3): 250-259.

Al-Mukhtar M, Lasledj A and Alcover JF (2010) Behaviour and mineralogy changes in lime-treated expansive soil at $20^{\circ} \mathrm{C}$. Applied Clay Science 50(3): 191-198. 
Asghari E, Toll DG and Haeri SM (2003) Triaxial behaviour of a cemented gravely sand, Tehran alluvium. Geotechnical and Geological Engineering 21(1): 1-28.

ASTM (2004) D 5102-96: Standard test method for unconfined compressive strength of compacted soil-lime mixtures. ASTM International, West Conshohocken, PA, USA.

Boardman D, Glendinning S and Rogers CDF (2001) Development of stabilisation and solidification in lime-clay mixes. Géotechnique 50(6): 533-543.

BSI (1990) BS 1377-8:1990: Methods of test for soils for civil engineering purposes. Shear strength tests (effective stress). BSI, London, UK.

Chen $\mathrm{H}$ and Wang D (2006) The behaviour of organic matter in the process of soft soil stabilization using cement. Bulletin of Engineering Geology and the Environment 65(4): 445-448.

Chen D, Si Z and Saribudak M (2009) Roadway heaving caused by high organic matter. Journal of Performance of Constructed Facilities 23(2): 100-108.

Choquette M, Andre Bérubé M and Locat J (1987) Mineralogical and microtextural changes associated with lime stabilization of marine clays from eastern Canada. Applied Clay Science 2(3): 215-232.

Chu J, Wanatowski D, Leong WK, Loke WL and He J (2015) Instability of dilative sand. Geotechnical Research 2(1): 35-48, http://dx.doi.org/10. 1680/gr.14.00015.

Davoudi MH and Kabir E (2011) Interaction of lime and sodium chloride in a low plasticity fine grain soils. Journal of Applied Sciences 11(2): 330-335.

Harris P, Harvey O, Sebesta S et al. (2009) Mitigating the Effects of Organics in Stabilized Soil. Texas Transportation Institute, College Station, TX, USA. Technical Report No. 0-5540-1.

Hebib S and Farrell ER (2003) Some experiences on the stabilization of Irish peats. Canadian Geotechnical Journal 40(1): 107-120.

Huat BB, Maail KS and Ahmed Mohamed T (2005) Effect of chemical admixtures on the engineering properties of tropical peat soils. American Journal of Applied Sciences 2(7): 1113-1120.

James R, Kamruzzaman AHM, Haque A and Wilkinson A (2008) Behaviour of lime-slag-treated clay. Proceedings of the Institution of Civil Engineers - Ground Improvement 161(4): 207-216.

Kang X, Kang G, Chang K and Ge L (2015) Chemically stabilized soft clays for road-base construction. Journal of Materials in Civil Engineering 27(7): 04014199

Kang G, Tsuchida T, Kim Y and Baek W (2017) Influence of humic acid on the strength behavior of cement-treated clay during various curing stages. Journal of Materials in Civil Engineering 29(8): 04017057.

Kazemian S, Huat BK and Barghchi M (2011) Effect of calcium chloride and kaolinite on shear strength and shrinkage of cement grout. International Journal of the Physical Sciences 6(4): 707-713.

Koslanant S, Onitsuka K and Negami T (2006) Influence of salt additive in lime stabilization on organic clay. Geotechnical Engineering Journal of the Southeast Asian Geotechnical Society 39: 95-101.

Kuno G, Kutara K and Miki H (1989) Chemical stabilization on soft soils containing humic acid. Proceedings of the 12th International Conference on Soil Mechanics Foundation Engineering, Rio de Janeiro, Brazil, vol. 2, pp. 1381-1384

Lade PV and Trads N (2014) The role of cementation in the behaviour of cemented soils. Geotechnical Research 1(4): 111-132, http://dx.doi. org/10.1680/gr.14.00011.

Likitlersuang S, Surarak C, Suwansawat S et al. (2014) Simplified finiteelement modelling for tunnelling-induced settlements. Geotechnical Research 1(4): 133-152, http://dx.doi.org/10.1680/gr.14.00016.

Marks BD and Haliburton TA (1999) Effects of sodium chloride and sodium chloride-lime admixtures on cohesive Oklahoma soils. Highway Research Record 315: 102-111.
Modmoltin C and Voottipruex P (2009) Influence of salts on strength of cement-treated clays. Proceedings of the Institution of Civil Engineers - Ground Improvement 162(1): 15-26.

Mohd Yunus NZ, Wanatowski D and Stace LR (2011) Effect of humic acid and salt additives on the behavior of lime-stabilised organic clay. In Second International Conference on Geotechnique, Construction Materials and Environment, Kuala Lumpur, Malaysia, 14-16 November (Hossain MZ and Huat BBK (eds)). GEOMATE, Tsu, Japan, pp. 253-256.

Mohd Yunus NZ, Wanatowski D and Stace LR (2012) Effectiveness of chloride salts on the behaviour of lime-stabilised organic clay. International Journal of GEOMATE 3(2): 407-412.

Mohd Yunus NZ, Wanatowski D and Stace LR (2013a) Lime stabilisation of organic clay and the effects of humic acid contents. Geotechnical Engineering Journal of SEAGS \& AGSSEA 44(1): 19-25.

Mohd Yunus NZ, Wanatowski D, Stace LR, Abdullah N and Abdullah RA (2013b) Effect of humic acid on microstructure of lime-treated organic clay. International Journal of Engineering Research and Technology 2(11): 1827-1833.

Mohd Yunus NZ, Wanatowski D, Stace LR et al. (2014) Undrained \& drained behavior of lime-treated organic clay with calcium chloride $\left(\mathrm{CaCl}_{2}\right)$. Electronic Journal of Geotechnical Engineering 19(H): 1596-1610.

Mohd Yunus NZ, Marto A, Pakir F et al. (2015) Performance of lime-treated marine clay on strength and compressibility characteristics. International Journal of GEOMATE 8(2): 1232-1238.

Mokhtar M and Swamy RN (2010) Influence of salt weathering on the properties of concrete. Arabian Journal for Science and Engineering 33(1B): 105-116

Murty VR and Krishna PH (2007) Amelioration of expansive clay slopes using calcium chloride. Journal of Materials in Civil Engineering 19(1): $1-19$.

Onitsuka K, Modmoltin C and Kouno M (2001) Investigation on microstructure and strength of lime and cement stabilized Ariake clay. Reports of the Faculty of Science and Engineering, Saga 30(1): 49-63.

Onitsuka K, Modmoltin C, Kouno M and Negami T (2002) The effect of humic acid on lime stabilized Ariake Clay. Proceedings of the Twelfth International Offshore and Polar Engineering Conference. Kitakyushu, Japan, paper I-02-223.

Onitsuka K, Modmoltin C, Kouno M and Negami T (2003) Effect of organic matter on lime and cement stabilized Ariake clays. Journal of Geotechnical Engineering JSCE 2003(729): 1-13.

Petry TM and Glazier EJ (2004) The Effect of Organic Content on Lime Treatment of Highly Expansive Clay. University of Missouri-Rolla, Rolla, MO, USA, project report.

Rajasekaran G and Rao N (1997) The microstructure of lime-stabilized marine clay. Ocean Engineering 24(9): 867-875.

Ramana Murty V and Hari Krishna P (2006) Stabilisation of expansive clay bed using calcium chloride solution. Ground Improvement 10(1): 39-46.

Ramesh HN, Siva Mohan M and Sivapullaiah PV (1999) Improvement of strength of fly ash with lime and sodium salts. Ground Improvement 3(4): 163-167.

Sakr M and Shahin MA (2009) Utilization of lime for stabilizing soft clay soil of high organic content. Geotechnical and Geological Engineering 27(1): 105-113.

Sharma RS, Phanikumar BR and Varaprasada Rao B (2008) Engineering behaviour of a remolded expansive clay blended with lime, calcium chloride, and rice-husk ash. Journal of Materials in Civil Engineering 20(8): 509-515.

Stipho A (1989) Some engineering properties of stabilized salina soil. Engineering Geology 26(2): 181-197. 
Geotechnical Research

Volume 4 Issue GR4
Strength improvement of lime-treated

clay with sodium chloride

Mohd Yunus, Wanatowski, Marto and Jusoh
Thangavel K, Muralidharan S and Saraswathy V (2010) Relationship between alumina and chloride content on their physical and corrosion resistance properties of concrete. Arabian Journal for Science and Engineering 35: 27-39.
Zhu W, Chiu CF, Zhang CL and Zeng K (2009) Effect of humic acid on the behaviour of solidified dredged material. Canadian Geotechnical Journal 46(9): 1093-1099.

\section{How can you contribute?}

To discuss this paper, please submit up to 500 words to the editor at journals@ice.org.uk. Your contribution will be forwarded to the author(s) for a reply and, if considered appropriate by the editorial board, it will be published as a discussion in a future issue of the journal. 